\title{
Fibronectin-like Immunoreactivity in the Developing Cerebral Cortex
}

\author{
Gregory R. Stewart and Alan L. Pearlman \\ Departments of Cell Biology and Neurology, Washington University School of Medicine, St. Louis, Missouri 63110
}

In the developing cerebral cortex of the mouse, binding of antibodies directed against the extracellular matrix glycoprotein fibronectin occurs with a distinct temporal and spatial pattern. On the 10th embryonic day (E10), when the wall of the telencephalic vesicle is made up of only the proliferating cells of the ventricular zone, antifibronectin (aFN) binding is restricted to the blood vessels and pia-arachnoid. Fibronectin-like immunoreactivity first appears in the neuropil as small points of immunofluorescence among the earliest postmitotic neurons that form the preplate (E11-12). A short time later (E12-13), aFN immunoreactivity becomes more diffuse but continues to be restricted to the preplate. As newly arriving neurons form the cortical plate within the preplate (E13-14), aFN binding is present in the marginal zone above the cortical plate and in the subplate below it. Both the marginal zone and the subplate contain early afferents and the cells that were previously part of the preplate. Binding of aFN is transient; by E18-19 it has diminished to the point where it is no longer detectable except in the blood vessels and pia-arachnoid.

The transient appearance of fibronectin-like immunostaining in the zones that contain early cortical afferents suggests that fibronectin plays a role in forming the migratory pathway for the growth cones of these axons. In this role it may be acting in concert with other extracellular matrix components such as hyaluronectin, glycosaminoglycans, and laminin, which have been shown to have similar spatial distributions. The decline of fibronectin-like immunostaining that occurs as cortical development progresses may be a part of the change from the Immature state, which supports profuse axon elongation in the CNS, to the mature state in which neurite outgrowth is quite limited.

Two major migrations take place during the early stages of formation of the mammalian cerebral cortex. Cells destined to become cortical neurons move from the site of their generation, the proliferative zone adjacent to the cerebral ventricle, to the particular cortical layer where they will subsequently reside.

\footnotetext{
Received Jan. 23, 1987; revised Apr. 22, 1987; accepted Apr. 28, 1987.

We are very grateful to Drs. Richard Hynes, John McDonald, and John Wood for providing antibodies used in this study. We thank Jeanette Cohen and Gail Schmitt for their expert assistance with photography and immunohistology. This work was supported by National Institutes of Health Research Grant R01 EY 00621 from the National Eye Institute and Training Grant T32 NS 07057 from the National Institute of Neurological and Communicative Disorders and Stroke

Correspondence should be addressed to Alan L. Pearlman, M.D., Department of Cell Biology, Washington University School of Medicine, 4566 Scott Avenue, St. Louis, MO 63110.

Copyright (C) 1987 Society for Neuroscience $0270-6474 / 87 / 103325-09 \$ 02.00 / 0$
}

Axonal growth cones, some beginning their journey in the cortex and others arriving from great distances, traverse defined pathways to terminate on specific neuronal targets. Cortical neurons appear to be guided in their migration by radial glia (Ramon y Cajal, 1911; Rakic, 1972); very little is known regarding the terrain over which the growth cones of afferent and efferent axons make their way.

Several lines of evidence indicate that an extracellular matrix (ECM) serves as a substrate for the migration of neurons and the extension of axons of the PNS during development. Fibronectin, a large, dimeric glycoprotein present in extracellular matrices and basement membranes (Hynes and Yamada, 1982), appears in the migratory pathway of neural crest cells just before migration begins and declines as migration ends (Newgreen and Thiery, 1980; Mayer et al., 1981). Fibronectin also promotes the attachment of ncural crest cclls to collagen substrates in tissue culture (Greenberg et al., 1981) and enhances their migration (Newgreen et al., 1982). Both fibronectin and laminin, another ECM glycoprotein, are effective in promoting the outgrowth of neurites from a variety of central and peripheral neurons in tissue culture (Hauschka and Ose, 1979; Akers et al., 1981; Manthorpe et al., 1983; Rogers et al., 1983; Liesi et al., 1984; Smallheiser, 1984).

Recent evidence indicates that ECM components might also play a role in the development of the CNS. Fibronectin-like immunoreactivity is present in the initial parts of the migratory pathway of granule cell precursors over the surface of the cerebellum (Hatten et al., 1982), but it has thus far not been demonstrable in the developing forebrain except in association with the cells of the blood vessels and pia (Schachner et al., 1978; Minier et al., 1981). During development of the optic nerve of the goldfish, axons extend in apposition to a basal lamina (Easter et al., 1984). Colloidal iron and alcian blue have been used to indicate the presence of glycosaminoglycans in the subplate and marginal zones of the developing cerebral cortex of the mouse (Derer and Nakanishi, 1983; Nakanishi, 1983). Similar dyes were used to demonstrate a structured ECM in the chick's optic tectum just ahead of arriving optic nerve axons (Krayanek, 1980). Immunoreactivity to antibodies against hyaluronectin (Bignami and Delpech, 1985) and laminin (Liesi, 1985) has been demonstrated in the developing CNS of the rat.

In view of the evidence that ECM plays an important role in many aspects of the development of the PNS, and the recent evidence that it may also do so in the CNS, we examined the spatial and temporal distribution of fibronectin-like immunoreactivity during the development of the cerebral cortex of the mouse. We also stained neuronal processes with antibodies against neurofilaments to determine whether the distribution of nearly cortical afferents corresponds to that of fibronectin-like 

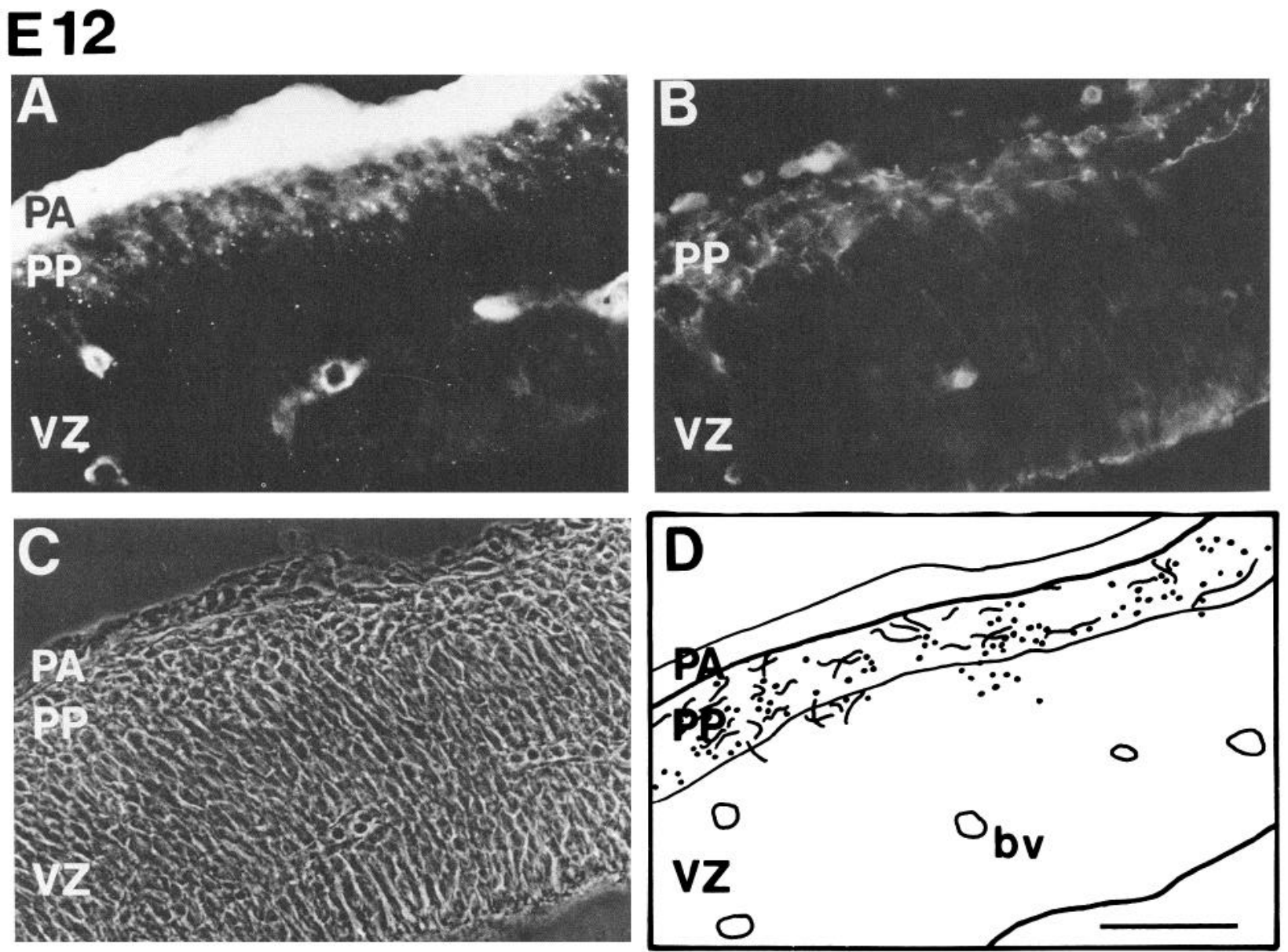

Figure 1. Distribution of binding of antifibronectin antibody (aFN) and antineurofilament antibody (aNF) in the dorsolateral wall of the telencephalon at E12. All photographs are of the same section, which has been double-labeled. $A$, Fluorescence (TRITC) photomicrograph showing punctate and diffuse aFN binding in the preplate $(P P)$, as well as bright staining of the pia-arachnoid $(P A)$ and the blood vessels; there is little or no staining in the ventricular zone $(V Z)$. $B$, Fluorescence (FITC) image showing binding of aNF to nerve fibers within the preplate. $C$, Phase image; the preplate is evident as a layer of cells that are more rounded than those of the ventricular zone. $D$, Superimposed tracings of Figures $A$ and $B$ to show the overlap in distribution of punctate fibronectin-like immunoreactivity and neurofilament positive neuronal processes. The solid line indicating the inferior aspect of the preplate was drawn from the phase image and is somewhat arbitrary since this border is difficult to determine with certainty. The fibers and punctate aFN binding shown below this line probably indicate irregularities in the preplate that are not obvious in the phase image. $b v$, blood vessel. Scale bar, $50 \mu \mathrm{m}$.

immunoreactivity. A preliminary report of our findings has appeared elsewhere (Pearlman et al., 1984).

\section{Materials and Methods}

Timed pregnancies. Matings of C57BL/6J mice (Jackson Labs, Bar Harbor, ME) were carried out by placing 1 male and 2 or 3 females together overnight and then separating them the next morning (E0). Each embryo was staged based on body and brain morphology (Rugh, 1968; Theiler, 1972) at the time of fixation, as well as on subsequent histological examination of the brain to adjust for variations in developmental age within a litter.

Embryos were removed under ether anesthesia. The brains were immersed in phosphate-buffered $4 \%$ paraformaldehyde $(\mathrm{pH} \mathrm{7.5)}$ for $1 \mathrm{hr}$, then in $30 \%$ sucrose overnight. Frozen sections $(8-20 \mu \mathrm{m})$ were cut on a cryostat (IEC Minotome), thawed onto gelatin-coated slides, and stored at $-20^{\circ} \mathrm{C}$ until processed for immunohistology.

Antibodies. The principal antifibronectin (aFN) antibody employed in this study was an affinity-purified rabbit antibody against human plasma fibronectin provided by Dr. J. McDonald (Villiger et al., 1981). A rabbit anti-hamster cellular aFN obtained from Dr. R. Hynes (Mautner and Hynes, 1977; Schwarzbauer et al., 1983) produced an identical but somewhat less intense staining pattern. The antineurofilament antibody (aNF) was a monoclonal antibody (RT97) obtained from Dr. J. Wood that cross-reacts with both the 150 and $200 \mathrm{kDa}$ molecular weight subunits of neurofilaments (Anderton et al., 1982; Wood et al., 1985).
As a control for specificity of staining, aFN was replaced with the immunoglobulin fraction from nonimmune rabbit serum (Cappel), diluted to a protein concentration equivalent to aFN. As an additional control, aFN was preadsorbed with purified FN (supplied by Dr. J. McDonald) and the antigen-antibody complex removed by several passages over a collagen substrate prior to incubation with sections.

Immunohistochemistry. All incubations were carried out in a darkened, humidified chamber at room temperature. Sections were washed in PBS (pH 7.5) for $5 \mathrm{~min}$, incubated with aFN (diluted 1:30 or 1:50; final protein concentration $0.025 \mathrm{mg} / \mathrm{ml}$ ) for $1 \mathrm{hr}$, washed in PBS, incubated with fluorescein (FITC)-conjugated goat anti-rabbit immunoglobulins (1:100; Cappel) for $30 \mathrm{~min}$, washed in PBS, and coverslipped after application of paraphenylamine diamine in glycerine (Johnson and Nogueira-Araugo, 1981) or 1,4-diazobicyclo(2,2,2)octane (Aldrich) in Gelvatol (Monsanto). All immunoreagents were diluted to desired concentrations with PBS. Secondary antibodies were incubated for $30 \mathrm{~min}$ with a homogenate of brains from adult mice prior to application. This procedure substantially reduced nonspecific binding of the secondary to sections.

In double-labeling experiments with $\mathrm{aFN}$ and antineurofilament antibodies, the aFN labeling procedure was carried out as described above except that rinses and dilutions were in Tris-buffered saline (TBS) and the secondary antibody was a goat anti-rabbit IgG (H\&L; Jackson Immunoresearch), labeled with rhodamine (TRITC) diluted 1:100. After fixation for $5 \mathrm{~min}$ with $95 \%$ ethanol-5\% acetic acid, the sections were rinsed 3 times with TBS, incubated for $1 \mathrm{hr}$ with the antineurofilament 

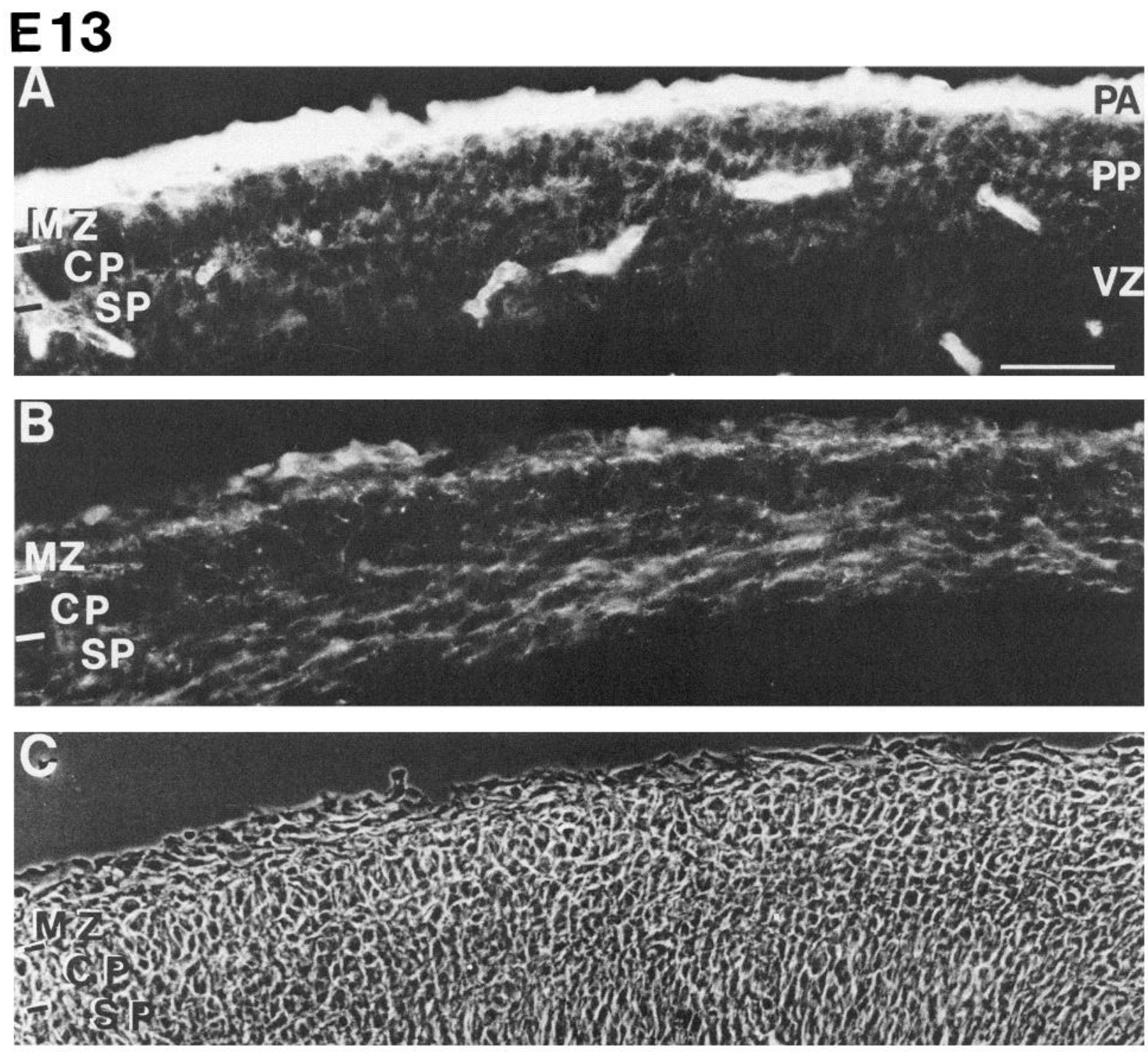

Figure 2. Distribution of binding of aFN and aNF in the dorsal wall of the telencephalon on E13. The photographs are of the transitional zone in which the cortical plate $(C P)$ is forming within the preplate $(P P)$ as maturation proceeds in the lateral (left) to medial (right) direction. All photographs are of the same section, which has been double-labeled. $A$, Fluorescence (TRITC) photomicrograph showing diffuse fibronectin-like immunoreactivity in the preplate on the right and in the subplate $(S P)$ and marginal zone $(M Z)$ on the left. $B$, Neuronal processes containing neurofilaments are evident in the preplate on the right and in the subplate and marginal zones on the left (FITC fluorescence). $C$, Phase image. Scale bar, $50 \mu \mathrm{m}$.

primary (1:500), washed 3 times with TBS, incubated for 30 min with FITC-conjugated goat anti-mouse IgG (H\&L; Jackson Immunoresearch), washed, mounted in Gelvatol, and coverslipped. Separate control sections were incubated with TBS substituted for each of the primary antibodies. Selected sections adjacent to those used for immunofluorescence were stained with diluted Richardson's stain (methylene blue and azure II in sodium borate buffer).

Sections were examined with a microscope (Nikon Labophot) equipped for epifluorescence, phase, and bright-field illumination. Epifluorescence illumination was provided by a mercury arc bulb $(100 \mathrm{~W})$, with filter cubes optimized for FITC (Nikon B2) and TRITC (Nikon G1B). Photographs were taken with a $35 \mathrm{~mm}$ camera attachment (Nikon HBO) on high-speed film (Kodak Tri-X) that was developed in Diafine.

\section{Results}

Brains of mice ranging in age from E10 through birth (E19) were fixed, sectioned, and examined for immunoreactivity against aFN. Sections from early embryos were also double-labeled with an antibody to neurofilaments in order to determine the distri- bution of neuronal processes in relation to the zones containing fibronectin-like immunostaining.

At E10-11, the wall of the telencephalic vesicle consists of a pseudostratified columnar epithelium containing numerous mitotic figures. Immunoreactivity to $\mathrm{aFN}$ is restricted to the blood vessels and pia. At slightly later stages (E11-12), this layer of proliferating cells, called the ventricular zone (Boulder Committee, 1970) can be distinguished from a thin, superficial zone, the preplate, ${ }^{1}$ in which cell bodies are less densely packed. The

' This zone has also been called the marginal zone (Boulder Committee, 1970), the primordial plexiform zone (Marin-Padilla, 1978), and the pallial anlage (Rickman et al., 1977). We have elected to use the term preplate (Rickman et al., 1977) since current evidence indicates that the cortical plate forms within it. Preplate is similar in meaning to pallial anlage but has the advantage of relative simplicity. The term primordial plexiform zone (Marin-Padilla, 1978) takes account of the neuronal processes that are a prominent feature of this layer but does not call attention to the important early nerve cells that are also present. The term marginal zone will be used to designate the cell-sparse zone that is superficial to the cortical plate after it has formed within the preplate. 


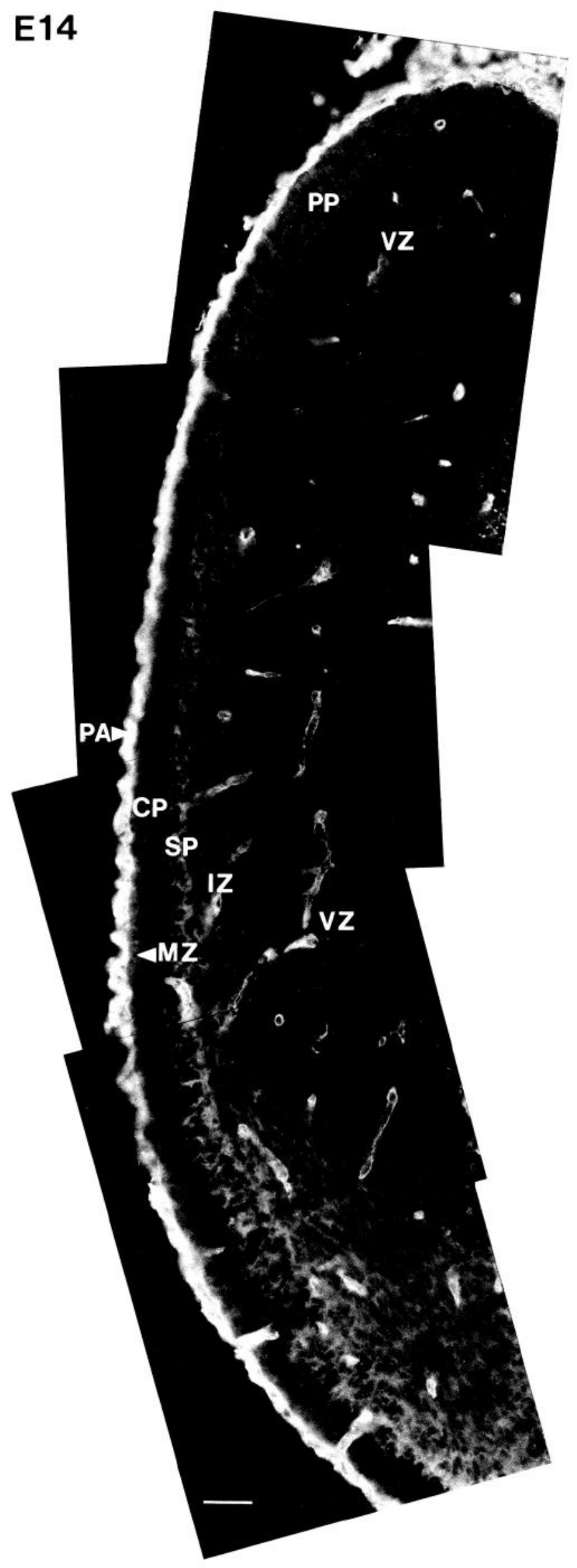

preplate contains the first population of young neurons to complete their final cell division and migrate out of the proliferative zone (Raedler and Raedler, 1978; Luskin and Shatz, 1985) and also contains early-arriving afferent axons (Rickman et al., 1977; Marin-Padilla, 1978). The source of these early afferents has not yet been clearly defined (Rickman et al., 1977).

Immunoreactivity to $\mathrm{aFN}$ is first encountered in the preplate very soon after it is formed (E11-12). Initially, small points of bright immunofluorescence are evident between cell bodies (Fig. $1 A)$ in a distribution that corresponds very closely to the territory occupied by neurofilament-containing fibers (Fig. 1, $B$, $D$ ). By E13 the aFN staining has become more diffuse within the preplate (Fig. $2 A$, right side; Fig. 3). Its distribution continues to coincide with the territory occupied by neurofilament-containing fibers (Fig. 2B).

The cortical plate forms within the preplate as a cell-dense layer of young neurons on E13-14. Cortical plate formation starts along the ventrolateral aspect of the telencephalic vesicle and proceeds dorsomedially, giving the cortical plate a wedgelike appearance in frontal sections (Figs. 2 and 3). As a consequence of cortical plate formation, the preplate is divided into the marginal zone above the cortical plate and the subplate below it; aFN binding is prominent in the subplate, with fainter staining in the marginal zone beneath the pia. On E14, the dorsal (Fig. 3) and medial (not shown) aspects of the cerebral wall are the least developed; they display the pattern of diffuse intercellular aFN staining in the preplate.

By E15 the cortical plate has formed throughout the cerebral mantle, which can be divided into 5 layers based on the relative content of cell bodies and neuronal processes (Crandell and Caviness, 1984; Luskin and Shatz, 1985). From pial to ventricular surface, these layers are (Fig. $4 A$ ) as follows: (1) the marginal zone, a cell-sparse, fiber-rich region; (2) the cell-dense cortical plate; (3) the cell-sparse, fiber-rich subplate; (4) the intermediate zone, composed of fibers and migrating neurons; and (5) the subventricular and ventricular zones, which are sites of continuing cytogenesis (Boulder Committee, 1970; Kostovic and Molliver, 1974).

Immunoreactivity to aFN continues to be prominent in the subplate on E15 (Fig. 4B); it is particularly evident in tangential sections that pass through the subplate (Fig. $4 C$ ). In addition, fine, fiber-like projections of immunoreactivity extend upward from the subplate into the cortical plate (Fig. 4B). Less intense immunostaining is also present in the marginal zone and in the upper aspect of the intermediate zone. Fibronectin-like immunoreactivity diminishes from E16 onward; by E18-19 it is

Figure 3. Distribution of fibronectin-like immunoreactivity in the lateral telencephalic wall at E14. Montage of several low-power fluorescence (FITC) photomicrographs of a frontal section; the dorsal aspect of the hemisphere is at the top and the lateral aspect is to the left. The diffuse pattern of aFN binding characteristic of the preplate $(P P)$ is present in the less developed dorsal aspect. In the ventrolateral aspect the cortical plate $(C P)$ has formed; it is evident as a dark wedge extending upward from the bottom of the montage along the left side. Fibronectinlike immunoreactivity is prominent in the subplate $(S P)$ and present in the upper part of the intermediate zone $(I Z)$ and the internal capsule at the base of the figure. It is also present above the cortical plate in the marginal zone $(M Z)$ but is difficult to demonstrate because of the intense staining of the pia-arachnoid $(P A)$. Scale bar, $50 \mu \mathrm{m}$. 


\section{E15}
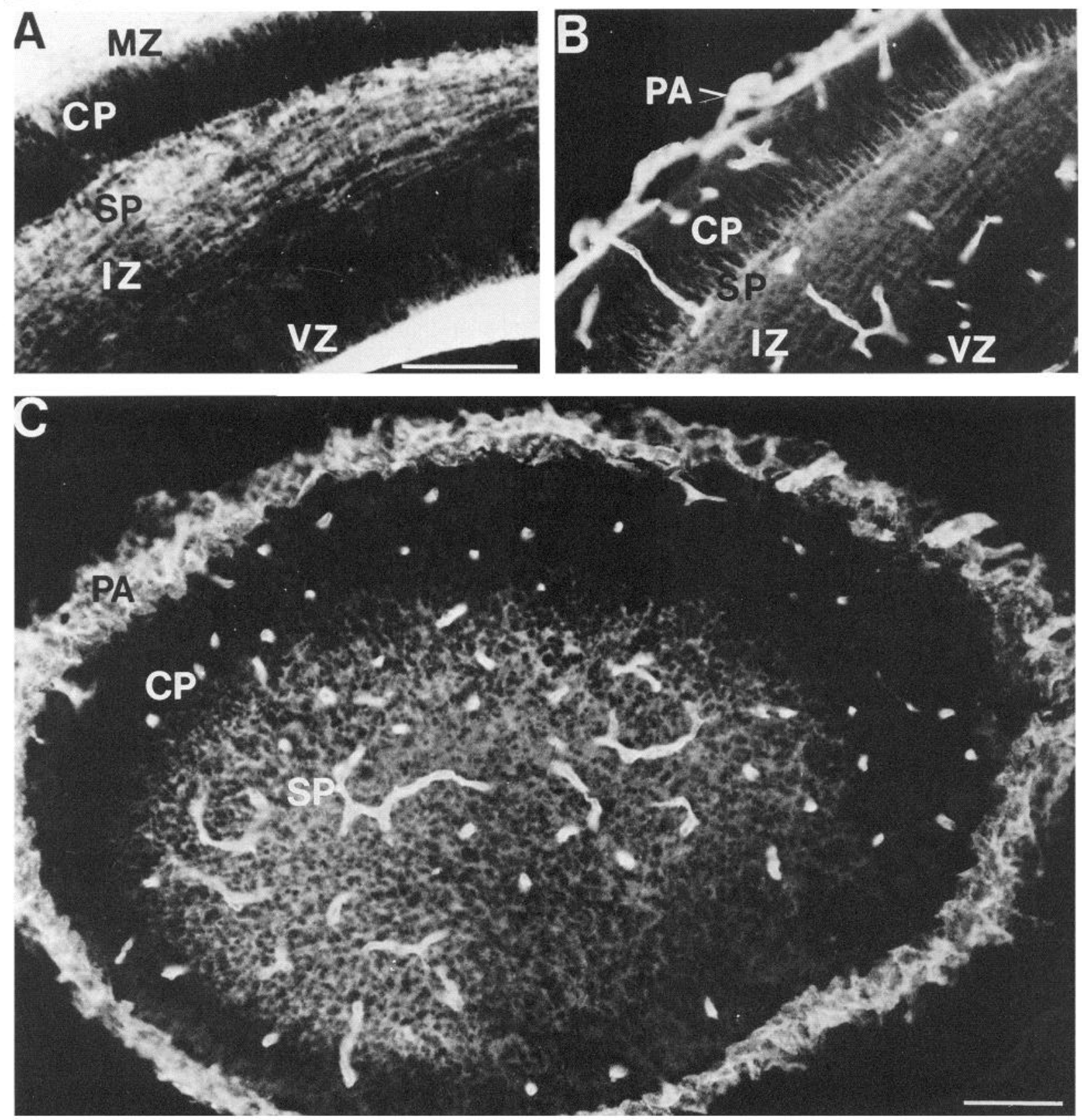

Figure 4. A, Laminar pattern of cortex at E15. In this Nissl-stained coronal section of the dorsolateral telencephalic wall, 5 layers are evident: the marginal zone $(M Z)$, the cortical plate $(C P)$, the subplate $(S P)$, the intermediate zone $(I Z)$, and the ventricular zone $(V Z)$. Scale bar, $100 \mu$ m. $B$, Fluorescence (FITC) micrograph of an adjacent section showing aFN binding in the subplate, with fine fingers of staining extending into the cortical plate. Less distinct staining is also present in the upper aspect of the intermediate zone. Scale same as $A$. $C$, Tangential section of the lateral aspect of the telencephalic wall passing through the subplate, which has prominent fibronectin-like immunoreactivity. The cortical plate and piaarachnoid $(P A)$ appear as rings since the section is tangential to the spherical cortical surface. Scale bar, $100 \mu \mathrm{m}$.

no longer present except in association with the pia and blood vessels (Fig. 5).

Controls. In each experiment, several sections were incubated with nonimmune IgG rather than aFN (Fig. $6 B$ ). In other controls, aFN was preincubated with fibronectin (Fig. $6 C$ ). No staining of neuropil, blood vessels, or pia-arachnoid was evident in either case.

\section{Discussion}

\section{Specificity of immunostaining}

There seems little doubt that the immunostaining associated with the blood vessels and pia is the result of binding to fibronectin, since fibronectin immunoreactivity has been demonstrated in these locations many times (Schachner et al., 1978; 


\section{E18}

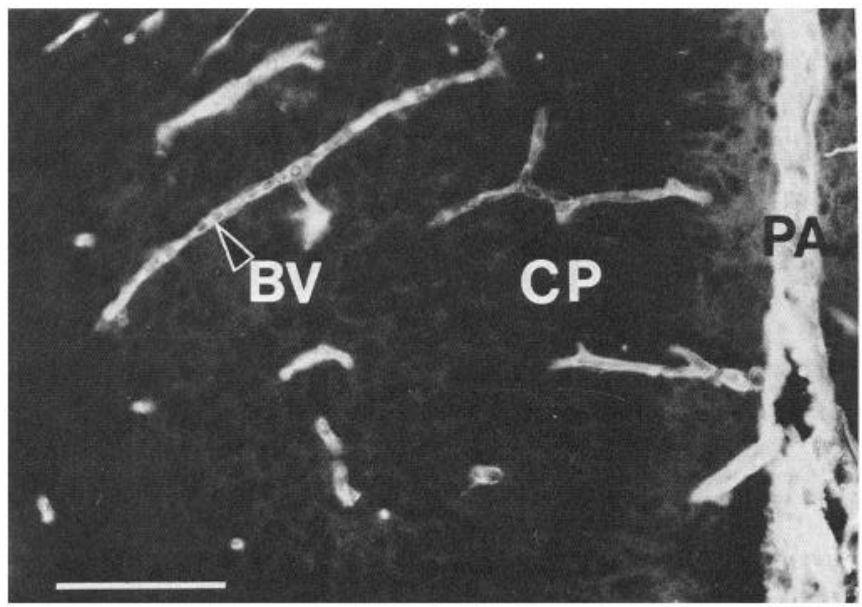

Figure 5. By E18, aFN binding has declined in the neuropil and is present only in association with blood vessels $(B V)$ and pia-arachnoid $(P A)$. Fluorescence (FITC) micrograph of medial cortex adjacent to interhemispheric fissure in a frontal section. Scale bar, $100 \mu \mathrm{m}$.

Jones et al., 1982; Liesi, 1985). It is the transient staining in the preplate, marginal zone, and subplate that is the new finding, and it is the specificity of this staining that must be considered.

For most of our observations we used a polyclonal antibody against human plasma fibronectin that was affinity-purified with fibronectin (Villiger et al., 1981), enhancing the likelihood that the binding of this antibody in our sections is to a molecule having epitopes in common with fibronectin. This conclusion is supported by the observations that (1) antibody binding is blocked by preincubating the antibody with fibronectin and (2) a second polyclonal antibody, produced in a different laboratory against cellular fibronectin from the hamster (Mautner and Hynes, 1977; Schwarzbauer et al., 1983), results in the same pattern of immunofluorescence, although staining is less intense. We therefore conclude that the material present in the neuropil that binds aFN antibodies is, at minimum, fibronectin-like in that it shares at least one, and probably more than one, antigenic determinant with fibronectin.

In the context of this consideration of the specificity of our immunostaining, it is of note that there are discrepancies in the literature regarding the detection of fibronectin as well as laminin by immunohistological methods in the developing brain. Several laboratories have reported that aFN binding in the brain is limited to the blood vessels and meninges (Schachner et al., 1978; Jones et al., 1982; Liesi, 1985). However, a recent preliminary report (Chun et al., 1986) describes fibronectin-like immunoreactivity in the developing cortex of the cat in a distribution quite similar to that reported here and also described in our earlier abstract (Pearlman et al., 1984). Similarly, immunostaining with antibodies to laminin was initially observed only in association with the blood vessels and meninges (Bignami et al., 1984), whereas it has recently been described in and between cells in several brain regions (Liesi, 1985; Madsen et al., 1986). Although the reasons for these discrepancies are not yet clear, the sensitivity of immunostaining to a wide range of variables, including affinity of the antibody and method of fixation, leads us to give greater weight to a well-controlled positive result than to a negative one.

\section{ECM components in the developing CNS}

Although fibronectinlike-immunoreactivity has not previously been observed in the neuropil of the developing forebrain (Schachner et al., 1978; Jones et al., 1982), it has been seen in the developing cerebellum. Hatten et al. (1982) found fibronectin-like immunoreactivity along the initial stages of the route of migration taken by the cells forming the external granule cell layer in the mouse. They postulated a role for fibronectin in this neuronal migration, which is of particular interest since the migration is not associated with radial glia. Their postulate has
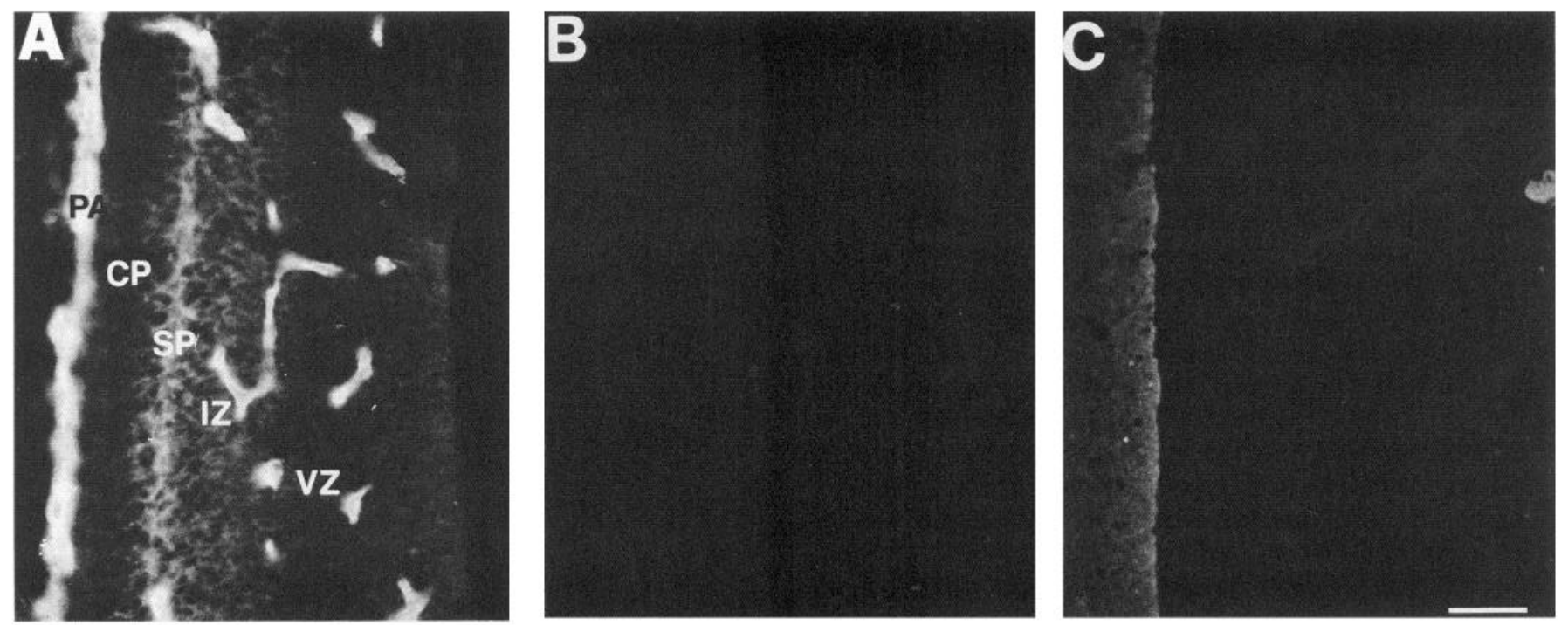

Figure 6. Controls. A, Fibronectin-like immunoreactivity demonstrable in subplate $(S P)$ of medial cortex adjacent to interhemispheric fissure on E15 after standard reaction procedure (FITC fluorescence). B. Adjacent section; nonimmune rabbit IgG was substituted for aFN. $C$, Adjacent section; aFN was preincubated with fibronectin prior to application to section. Despite several passages of the mixture over a collagen substrate before application, a small amount of the aFN-fibronectin complex has adhered to the gelatin-coated slide to the left of the section, producing slight fluorescence; aFN binding to the section has been blocked. Scale bar, $50 \mu \mathrm{m}$. 
been challenged by Hynes et al. (1986), who did not find evidence for the presence of fibronectin, but instead suggested that cells migrating into the external granule layer do so along a set of early-arriving axons. This discrepancy remains to be resolved.

Several other ECM components have been observed transiently during the development of the mammalian CNS. Material that stains with colloidal iron and alcian blue is present in the preplate, marginal zone, and subplatc of the devcloping cortex of the mouse, suggesting the presence of glycosaminoglycans (Nakanishi and Derer, 1982; Derer and Nakanishi, 1983; Nakanishi, 1983). Antibodies to hyaluronectin, an ECM glycoprotein that specifically binds hyaluronate, stain in a very similar distribution in the rat (Bignami and Delpech, 1985). Extracellular material is evident with electron microscopy in the subplate (Derer and Nakanishi, 1983; Nakanishi, 1983; Hankin and Silver, 1986) and marginal zones (Derer and Nakanishi, 1983; Nakanishi, 1983).

Antilaminin immunoreactivity is present in the developing brain of the rat (Liesi, 1985; Madsen et al. 1986). In early stages (E8-10) it is present within all of the cells of the cerebral wall; slightly later (E12-18) it is also prominent as punctate deposits along the radial glia of the cerebral hemispheres, diencephalon, and mesencephalon (Liesi, 1985). Antilaminin immunoreactivity gradually disappears from all of these locations prior to birth, but is expressed along the Bergmann glia of the cerebellum in the first few postnatal weeks, as well as within the astrocytes of the cerebellar white matter, the cells of the external granular layer, and the Purkinje cells (Liesi, 1985).

\section{Possible role of ECM in cortical development}

Our principal evidence regarding the role of fibronectin in the development of the mammalian cerebral cortex stems from the transient distribution of fibronectin-like immunoreactivity in the cortical preplate and in the marginal zone and subplate after cortical plate formation. Since this distribution corresponds to that of early cortical afferents, we suggest that fibronectin is associated with the ingrowth of these fibers.

Early cortical afferents are confined to the preplate (MarinPadilla, 1978), which is also the zone in which the earliest cortical neurons, the Cajal-Retzius cells and future subplate cells, are extending processes horizontally (Retzius, 1893; Ramon y Cajal, 1911; Astrom, 1967; Sas and Sanides, 1970; Marin-Padilla, 1971, 1972; Bradford et al., 1977; Rickman et al., 1977). Subsequent to cortical plate formation, cortical afferents, many from the thalamus, run in a dense fiber plane tangential to the cortical plate within the deeper portions of the subplate; individual fibers ascend and ramify at the interface between cortical plate and subplate (Crandall and Caviness, 1984). Monoaminergic afferents, which are among the early cortical arrivals, are also confined initially to the marginal zone and subplate (Schlumpf et al., 1980; Caviness and Korde, 1981; Lidov and Molliver, 1982; Verney et al., 1982).

At present, the experimental evidence regarding the role of fibronectin in promoting neurite outgrowth stems primarily from tissue culture studies and is conflicting. Fibronectin has been shown to promote neurite outgrowth from retinal neurons of the chick in vitro (Hauschka and Ose, 1979; Akers et al., 1981). However, Rogers et al. (1983) found that, while neurites of both CNS and PNS neurons from the chick grow well on laminin, only PNS neurites grow on fibronectin (Rogers et al., 1983). Manthorpe et al. (1983) found that neurite outgrowth from neurons of the chick's CNS and PNS was better on laminin than fibronectin but that higher concentrations of fibronectin did promote outgrowth. A dependence on the concentration of fibronectin has also been seen for axons from explants of the retina of the mouse (Smalheiser et al., 1984). Although it would appear that laminin is better than fibronectin at promoting neurite outgrowth in culture (Liesi et al., 1984), the relevance of these observations for a particular system of fibers growing at a particular time in the CNS is not clear, in part because it is difficult to compare concentrations in culture with those present in vivo. In addition, available evidence indicates that fibronectin is only one of several ECM components present in the pathway of migrating growth cones. They may all be acting in concert to support neurite outgrowth (Chiu et al., 1986), whereas they are usually tested independently in culture.

Given that fibronectin, hyaluronectin (Bignami and Delpech, 1985), and glycosaminoglycans (Nakanishi and Derer, 1981; Nakanishi, 1983) are distributed in tangential laminae rather than along the entire length of the radial glia that are thought to be guiding neuronal migration, it is difficult to postulate a role for these ECM components in guiding this migration throughout its course. However, the presence of ECM components in the preplate, marginal zone, and subplate during much of the time that neurons are migrating into the cortical plate might provide a signal to the neurons that they have reached the end of their journey. Such a signal could aid in the consolidation of the cortical plate within the preplate and in the subsequent addition of new neurons to its upper border. In addition, the evidence that laminin-like immunoreactivity is present along radial glia and Bergmann glia may indicate that at least this ECM component plays a more direct role in neuronal migration (Liesi, 1985).

\section{Origin of intracortical fibronectin}

Since the preplate is the first zone to show aFN binding, one or more of the relatively few elements present within it is presumably producing or sequestering the fibronectin-like material. The cellular elements that are known to be present within the preplate include the terminal portions of the radial glia, the early cortical afferents, and the population of cells that will become Cajal-Retzius and subplate neurons (Retzius, 1893; Marin-Padilla, 1971, 1972; Raedler and Raedler, 1978; Luskin and Shatz, 1985). These same elements are present in the marginal zone and subplate after cortical plate formation.

The evidence as to which of these elements might be producing fibronectin-like material or other ECM components is at present circumstantial. Isolated astrocytes in vitro produce fibronectin (Kavinsky and Garber, 1979; Price and Hynes, 1985; Liesi et al., 1986). Astrocytes in culture also have been shown to contain antilaminin immunoreactivity (McLoon et al., 1986) and appear to be secreting laminin since the immunoreactivity is concentrated in the region of the Golgi apparatus after monensin treatment (Liesi et al., 1983). Whether the production of ECM components by astrocytes in culture is relevant to the fibronectin-like material we demonstrate is uncertain, in part because the cultured astrocytes were obtained from late embryonic (Liesi et al., 1983) or early postnatal rats (Price and Hynes, 1985; Liesi et al., 1986) at stages when only blood vessels and meninges demonstrate fibronectin-like immunoreactivity in the mouse.

The possibility that the Cajal-Retzius and subplate neurons might be producing ECM is intriguing, since both their location and transient nature suggest an important role in cortical de- 
velopment (Marin-Padilla, 1971, 1972, 1978; Raedler and Sievers, 1976; Kostovic and Rakic, 1980; Luskin and Shatz, 1985; Chun et al., 1987). Electron microscopy with colloidal iron staining has demonstrated a fibrillar matrix in close association with Cajal-Retzius neurons (Derer and Nakanishi, 1983), and fibronectin-like immunoreactivity is correlated with the presence of their counterparts in the subplate (Chun et al., 1986). These interesting cells also have the cytoplasmic organelles indicative of active secretion (Raedler and Sievers, 1976; Edmunds and Parnavelas, 1982; Derer and Nakanishi, 1983). There is at present no evidence to support the prospect that the advancing early afferents are producing ECM, although this possibility should be considered since there are strong structural similarities between the growth cones of axons and the leading edge of fibroblasts; fibroblasts produce fibronectin, and their attachment and migration in vitro are enhanced by it (Hynes and Yamada, 1982).

In summary, fibronectin-like immunoreactivity appears transiently in the laminae of the developing cerebral cortex of the mouse that contain the early-arriving cortical afferents. We therefore postulate that fibronectin-along with hyaluronectin, glycosaminoglycans, and perhaps laminin - plays a role in forming the pathway traversed by the growth cones of early afferents. These ECM components are also located in the proper position to play a role in the consolidation of the cortical plate and in the final stages of the migration of the young cortical neurons that form it.

\section{References}

Akers, R. M., D. F. Moshier, and J. E. Lilien (1981) Promotion of retinal neurite outgrowth by substratum-bound fibronectin. Dev. Biol. 86: $179-188$.

Anderton, B. H., D. Breinburg, M. J. Downes, P. J. Green, B. E. Tomlinson, J. Ulrich, J. N. Wood, and J. Kahn (1982) Monoclonal antibodies show that neurofibrillary tangles and neurofilaments share antigenic determinants. Nature 298: 84-86.

Astrom, K.-E. (1967) On the early development of the isocortex in fetal sheep. In Progress in Brain Research. Developmental Neurology, C. G. Bernhard and J. P. Schade, eds., pp. 1-59, Elsevier, Amsterdam.

Bignami, A., and B. Delpech (1985) Extracellular matrix glycoprotein (hyaluronectin) in early cerebral development. Int. J. Dev. Neurosci. 3: 301-307.

Bignami, A., N. H. Choi, and D. Dahl (1984) First appearance of laminin in peripheral nerve, cerebral blood vessels and skeletal muscle of the rat embryo. Immunofluorescence study with laminin and neurofilament antisera. Int. J. Dev. Neurosci. 2: 367-376.

Boulder Committee (1970) Embryonic vertebrate central nervous system: Revised terminology. Anat. Rec. 166: 257-262.

Bradford, R., J. G. Parnavelas, and A. R. Lieberman (1977) Neurons in layer I of the developing occipital cortex of the rat. J. Comp. Neurol. 176: 121-132.

Caviness, V. S., Jr., and M. G. Korde (1981) Monoaminergic afferents to the neocortex: A developmental histofluorescence study in normal and reeler mouse embryos. Brain Res. 209: 1-9.

Chiu, A. Y., W. D. Matthew, and P. H. Patterson (1986) A monoclonal antibody that blocks the activity of a neurite regeneration-promoting factor: Studies on the binding site and its localization in vivo. J. Cell Biol. 103: 1383-1398.

Chun, J. J. M., M. J. Nakamura, and C. J. Shatz (1986) Transient fibronectin-like immunostaining in the subplate during development of the cat's telencephalon. Soc. Neurosci. Abstr. 12: 502.

Chun, J. J. M., M. J. Nakamura, and C. J. Shatz (1987) Transient cells of the developing mammalian telencephalon are peptide-immunoreactive neurons. Nature 325: 617-620.

Crandall, J. E., and V. S. Caviness (1984) Axon strata of the ccrebral wall in embryonic mice. Dev. Brain Res. 14: 185-195.

Derer, P., and S. Nakanishi (1983) Extracellular matrix distribution during neocortical wall ontogenesis in "normal" and "reeler" mice. J. Hirnforsch. 24: 209-224.
Easter, S. S., B. Bratton, and S. S. Scherer (1984) Growth-related order of the retinal fiber layer in goldfish. J. Neurosci. 4: 2173-2190.

Edmunds, S. M., and J. G. Parnavelas (1982) Retzius-Cajal cells: An ultrastructural study in the developing visual cortex of the rat. J. Neurocytol. 11: 427-446.

Greenberg, J. H., S. Seppa, H. Seppa, and A. T. Hewitt (1981) Role of collagen and fibroncctin in ncural crest cell adhesion and migration. Dev. Biol. 87: 259-266.

Hankin, M. H., and J. Silver (1986) Mechanisms of axonal guidance: The problem of intersecting fiber systems. In Developmental Biology, Vol. 2, L. W. Browder, ed., pp. 565-604, Plenum, New York.

Hatten, M. E., M. B. Furie, and D. B. Rifkin (1982) Binding of developing mouse cerebellar cells to fibronectin: A possible mechanism for the formation of the external granular layer. J. Neurosci. 2: 11951206.

Hauschka, S. D., and M. Ose (1979) In vitro requirements for neural retina ganglion cell axon formation. In Vitro 15: 204.

Hynes, R. O., and K. M. Yamada (1982) Fibronectins: Multifunctional modular glycoproteins. J. Cell Biol. 95: 369-377.

Hynes, R. O., R. Patel, and R. H. Miller (1986) Migration of neuroblasts along prcexisting axonal tracts during prenatal cerebellar development. J. Neurosci. 6: 867-876.

Johnson, G. D., and G. M. Nogueira-Araujo (1981) A simple method of reducing the fading of immunofluorescence during micruscopy. $\mathrm{J}$. Immunol. Methods 43: 349-350.

Jones, T. R., E. Ruoslahti, S. C. Schold, and D. D. Bigner (1982) Fibronectin and glial fibrillary acidic protein expression in normal human brain and anaplastic human gliomas. Cancer Res. 41: 168177.

Kavinsky, C. J., and B. B. Garber (1979) Fibronectin associated with the glial component of embryonic brain cell cultures. J. Supramol. Struct. 11: 269-281.

Kostovic, I., and M. E. Molliver (1974) A new interpretation of the laminar development of cerebral cortex: Synaptogenesis in different laycrs of ncopallium in the human fetus. Anat. Rec. 178: 395.

Kostovic, I., and P. Rakic (1980) Cytology and time of origin of interstitial neurons in the white matter in infant and adult human and monkey telencephalon. J. Neurocylol. 9: 219-242.

Krayanek, S. (1980) Structure and orientation of extracellular matrix in developing chick optic tectum. Anat. Rec. 197: 95-109.

Lidov, H. G. W., and M. E. Molliver (1982) An immunohistochemical study of serotonin neuron development in the rat: Ascending pathways and terminal fields. Brain Res. Bull. 8: 389-430.

Liesi, P. (1985) Do neurons in the vertebrate CNS migrate on laminin? EMBO J. 4: 1163-1170.

Liesi, P., D. Dahl, and A. Vaheri (1983) Laminin is produced by early rat astrocytes in primary culture. J. Cell Biol. 96: 920-924.

Liesi, P., D. Dahl, and A. Vaheri (1984) Neurons cultured from developing rat brain attach and spread preferentially to laminin. J. Neurosci. Res. 11: 241-251.

Liesi, P., T. Kirkwood, and A. Vaheri (1986) Fibronectin is expressed by astrocytes cultured from embryonic and early postnatal rat brain. Exp. Cell Res. 163: 175-185.

Luskin, M. B., and C. J. Shatz (1985) Studies of the earliest generated cells of the cat's visual cortex: Congeneration of the cells of the marginal zone and subplate. J. Neurosci. 5: 1062-1075.

Madsen, A., S. Palm, L. Furcht, and P. Letourneau (1986) Distribution of laminin and collagen type IV during early axonal growth in mouse CNS. Soc. Neurosci. Abstr. 12: 1210.

Manthorpe, M., E. Engvall, E. Ruoslahti, F. M. Longo, G. E. Davis, and $S$. Varon (1983) Laminin promotes neuritic regeneration from cultured peripheral and central neurons. J. Cell Biol. 97: 1882-1890.

Marin-Padilla, M. (1971) Early prenatal ontogenesis of the cerebral cortex (neocortex) of the cat (Felis domestica). A golgi study. I. The primordial neocortical organization. Z. Anat. Entwickl.-Gesch. 134: $117-145$.

Marin-Padilla, M. (1972) Prenatal ontogenetic history of the principal neurons of the neocortex of the cat (Felis domestica). A golgi study. Z. Anat. Entwickl.-Gesch. 136: 125-142.

Marin-Padilla, M. (1978) Dual origin of the mammalian neocortex and evolution of the cortical plate. Anat. Embryol. 152: 109-126.

Mautner, V., and R. O. Hynes (1977) Surface distribution of LETS protein in relation to the cytoskeleton of normal and transformed cells. J. Cell Biol. 75: 743-768.

Mayer, B. W., E. D. Hay, and R. O. Hynes (1981) Immunocytochem- 
ical localization of fibronectin in embryonic chick trunk and area vasculosa. Dev. Biol. 82: 267-286.

McLoon, S. C., L. K. McLoon, S. L. Palm, and L. T. Furcht (1986) Laminin is transiently expressed in the developing rat optic nerve during the time retinal axons are growing. Soc. Neurosci. Abstr. 12: 1211 .

Minier, L. N., R. S. Lasher, and P. F. Erickson (1981) Distribution of the LETS protein (fibronectin) in rat cerebellum. Cell Tissue Res. 214: 491-500.

Nakanishi, S. (1983) Extracellular matrix during laminar pattern formation of neocortex in normal and reeler mutant mice. Dev. Biol. 95: 305-316.

Nakanishi, S., and P. Derer (1982) Localisation de la matrice extracellulaire au cours de la corticogenese de la souris normale et du mutant reeler. Biol. Cell 42: $8 \mathrm{a}$.

Newgreen, D. L., and J. P. Thiery (1980) Fibronectin in early avian embryos: Synthesis and distribution along the migration pathways of neural crest cells. Cell Tissue Res. 211: 269-291.

Newgreen, D. F., I. L. Gibbins, J. Sauter, B. Wallenfels, and R. Wutz (1982) Ultrastructural and tissue-culture studies on the role of fibronectin, collagen and glycosaminoglycans in the migration of neural crest cells in the fowl embryo. Cell Tissue Res. 221: 521-549.

Pearlman, A. L., G. R. Stewart, and J. P. Cohen (1984) Fibronectinlike immunoreactivity in the developing neocortex of the mouse. Soc. Neurosci. Abstr. 10: 39

Price, J., and R. O. Hynes (1985) Astrocytes in culture synthesize and secrete a variant form of fibronectin. J. Neurosci. 5: 2205-2211.

Raedler, A., and J. Sievers (1976) Light and electron microscopical studies on specific cells of the marginal zone in the developing rat cerebral cortex. Anat. Embryol. 149: 173-181.

Raedler, E., and A. Raedler (1978) Autoradiographic study of early neurogenesis in rat neocortex. Anat. Embryol. 154: 267-284.

Rakic, P. (1972) Mode of cell migration to the superficial layers of fetal monkey neocortex. J. Comp. Neurol. 145: 61-84.

Ramón y Cajal, S. (1890) Sobre la existencia de celulas nerviosas especiales en la primera capa de las circunvoluciones cerebrales. Grac. Med. Catalana 3: 737-739.

Ramón y Cajal, S. (1911) Histologie du Systeme Nerveux de l'Homme et des Vertebres, Maloine, Paris.
Retzius, G. (1893) Die Cajal's chen zellen der grosshirnrinde beim menschen und bei saugethieren. Biol. Unters Neuefolge 1-8.

Rickmann, M., B. M. Chronwall, and J. R. Wolff (1977) On the development of nonpyramidal neurons and axons outside the cortical plate: The early marginal zone as a pallial anlage. Anat. Embryol. 151: 285-307.

Rogers, S. L., P. C. Letourneau, S. L. Palm, J. McCarthy, and L. T. Furcht (1983) Neurite extension by peripheral and central nervous system neurons in response to substratum-bound fibronectin and laminin. Dev. Biol. 98: 212-220.

Rugh, R. (1968) The Mouse. Its Reproduction and Development, Burgess, Minneapolis

Sas, E., and F. Sanides (1970) A comparative golgi study of Cajal foetal cells. Z. Mikrosk. Anat. Forsch. 82: 385-396.

Schachner, M., G. Schoonmaker, and R. O. Hynes (1978) Cellular and subcellular localization of LETS protein in the nervous system. Brain Res. 158: 149-158.

Schlumpf, M., W. J. Shoemaker, and F. E. Bloom (1980) Innervation of embryonic rat cerebral cortex by catecholamine-containing fibers. J. Comp. Neurol. 192: 361-376.

Schwarzbauer, J. E., J. W. Tamkun, I. R. Lemischka, and R. O. Hynes (1983) Three different fibronectin mRNAs arise by alternative splicing within the coding region. Cell 35: 421-431.

Smalheiser, N. R., S. M. Crain, and L. M. Reid (1984) Laminin as a substrate for retinal axons in vitro. Dev. Brain Res. 12: 136-140.

Theiler, K. (1972) The House Mouse, Springer-Verlag, Heidelberg.

Verney, C., B. Berger, J. Adrien, A. Vigny, and M. Gay (1982) Development of the dopaminergic innervation of the rat cerebral cortex. A light microscopic immunocytochemical study using anti-tyrosine hydroxylase antibodies. Dev. Brain Res. 5: 41-52.

Villiger, B., D. G. Kelley, W. Engleman, C. Kuhn, and J. A. McDonald (1981) Human alveolar macrophage fibronectin: Synthesis, secretion, and ultrastructural localization during gelatin-coated latex particle binding. J. Cell Biol. 90: 711-720.

Wood, J. N., N. B. Lathangue, D. R. McLachlan, B. J. Smith, B. H. Anderton, and A. J. Dowding (1985) Chromatin proteins share antigenic determinants with neurofilaments. J. Neurochem. 44:149154. 